\title{
Laterality In Parkinson's Disease: A Neuropsychological Review
}

Marilyn J. Steinbach, BS*, Benjamin B. DeVore, PhD, Ransom W. Campbell, PhD, David W. Harrison, $\mathrm{PhD}$

Psychology Department, Virginia Tech, Blacksburg, 24061, USA

*Corresponding author: mjstein@vt.edu 


\section{Laterality In Parkinson's Disease: A Neuropsychological Review}

Laterality of motor symptom onset in Parkinson's disease is both well-known and underappreciated. Treatment of disorders that have asymmetric pathological features, such as stroke and epilepsy, demonstrate the importance of incorporating hemispheric lateralization and specialization into therapy and care planning. These practices could theoretically extend to Parkinson's disease, providing increased diagnostic accuracy and improved treatment outcomes; however, laterality in Parkinson's disease has been largely ignored both clinically and in research. Additionally, while motor symptoms have generally received the majority of attention, non-motor features (e.g., autonomic dysfunction) also decrease quality of life and are influenced by asymmetrical neurodegeneration. Due to the laterality of cognitive and behavioral processes in the two brain hemispheres, analysis of hemibody side of onset can potentially give insight into expected symptom profile of the patient and allow for increased predictive accuracy of disease progression and outcome, thus opening the door to personalized and improved therapy in treating Parkinson's disease patients. This review discusses motor and non-motor symptoms (namely autonomic, sensory, visuospatial, language, and emotional dysfunction) of Parkinson's disease in respect to hemispheric lateralization from a theoretical perspective in hopes of providing a framework for future research and personalized treatment.

Key words: cerebral asymmetry, cerebral laterality, Parkinson's disease, autonomic nervous system, emotion theory 


\section{Disease background}

Over 200 years have passed since James Parkinson first described the disease to be named after him in his paper "An Essay on the Shaking Palsy" (Parkinson, 1817), yet many aspects of Parkinson's disease (PD) remain poorly understood. PD is a slowly progressing multisystem neurodegenerative disorder with symptoms that may include tremor, ataxia, bradykinesia, muscle rigidity, and dysphasia (Bartels \& Leenders, 2009; Ropper et al., 2014). More specifically, idiopathic PD is a synucleinopathy in which Lewy bodies and Lewy neurites accumulate in and destroy neurons. The loss of pigmented cells in the pars compacta of the substantia nigra and other pigmented nuclei depletes dopamine production (Ropper et al., 2014; Tysnes \& Storstein, 2017), and this loss of dopamine leads to the primary motor symptoms seen in PD (Gillies et al., 2014). Parkinson's Disease exists within a range of Parkinsonian Syndromes and is distinguished from these other similar diseases by its asymmetry in motor symptom onset as well as its excellent response to dopaminergic medication (Bartels \& Leenders, 2008; Ropper et al., 2014; Williams \& Litvan, 2013). Additionally, about 30\% of individuals with PD will go on to develop Parkinson's Disease Dementia (Aarsland et al., 2005).

While many of the etiological and pathogenic factors that contribute to PD have been determined, the exact causes of the disease remain uncertain (de Lau \& Breteler, 2006; Tysnes \& Storstein, 2017). The onset of PD is usually around 65-70 years old (de Lau \& Breteler, 2006) and affects $1 \%$ of the population over age 60 (Ferreira \& Massano, 2016). Men tend to experience a greater prevalence, earlier age of onset, and faster rate of progression (Jankovic \& Kapadia, 2001; Gillies et al., 2014), with men being 1.5-2 times as likely as women to develop PD (Baldereschi et al., 2000; de Lau et al., 2004; Wooten et al., 2004). Additionally, some symptoms, such as rigidity, appear more frequently in men (Baba et al., 2005; Martinez-Martin 
et al., 2012), while other symptoms, such as tremor, are more common in women (Haaxma et al., 2007; Martinez-Martin et al., 2012).

PD is characterized by four hallmark features: resting tremor, rigidity, bradykinesia, and postural instability (Jankovic, 2008). However, many non-motor symptoms, including those in sleep, cognition, autonomic functioning, and sensory perception, present further challenges to patients (Pfeiffer, 2016; Schapira et al., 2017). Additionally, some non-motor symptoms, such as olfactory disturbances and Rapid Eye Movement Sleep Behavior Disorder (RBD), can precede the onset of motor symptoms by years and may go unrecognized as these symptoms may not be attributed to PD (Chaudhuri et al., 2006). Interpreting both motor and non-motor symptoms in terms of hemispheric lateralization may shed light onto pathological changes and clinical manifestation.

\section{Hemispheric lateralization}

Recognized decades ago, the two hemispheres of the brain possess their own specializations in terms of cognition, arousal, and behavioral output (Benowitz et al., 1983; Gainotti, 1972; Geschwind, 1970; Luria, 1970; Milner, 1971). This is particularly evident when studying neurological disorders that are localized to one brain hemisphere with symptomology manifesting on the contralateral hemibody; for example, a patient with a left hemispheric stroke may exhibit right arm weakness. Treatment of disorders that have asymmetric pathological features demonstrate the importance of incorporating hemispheric lateralization and specialization into therapy and care planning. These practices could theoretically extend to PD, providing increased diagnostic accuracy and improved treatment outcomes; however, laterality in PD has been largely ignored both clinically and in research. 
The perceived role of hemispheric specialization and lateralization in cognitive and behavioral output has evolved over the years. While many models of how emotion and arousal are represented in the brain have been produced, such as the Right Hemisphere Model (Heilman \& Van Den Abell, 1980) and later the Valence Model (Sackeim et al., 1982; Silberman \& Weingartner, 1986), there lacks one model that cogently encapsulates temporally and dynamically the interplay between these functional neural systems that produce the cognitive and behavioral outputs. Therefore, the Dynamic Opponent Relativity Model (Comer et al., 2015), was proposed to incorporate the oppositional roles of the two hemispheres as they work to control the delicate balance of cognition. This model proposes that the oppositional hemisphere may still be maximally activated but inhibited by processes in the contralateral hemisphere. This places the hemispheres in a dynamic equilibrium, with each working to increase its lateralized processes by inhibiting the activity of the other hemisphere. Additionally, the model incorporates the limited capacity of the hemispheres (as oppositional forces will eventually exhaust their resources and result in dysregulation; see Klineburger and Harrison (2015) for a review on the Dynamic Functional Capacity Theory).

Within this context of dynamic functional balance, any substantive neuropathology can disrupt the equilibrium between the two hemispheres, leaving the damaged hemisphere inhibited and the other hemisphere disinhibited, dysregulated, and hyperactive (Borod, 1992; see Comer et al., 2015 for review). The inhibited hemisphere no longer possesses the ability to exert its influence over the other hemisphere and the rest of the body, meaning that it's specialized processes will be continually overpowered by those of the contralateral hemisphere, and its behavioral output may be reduced or absent. Without the checks and balance of the contralateral side, the disinhibited hemisphere will operate unregulated, and its normal processes will manifest 
in a superfluous, pathological fashion. This dysregulation then leads to aberrant behavioral and cognitive output that results in deficits or disorders due to disruption of the sensitive equilibrium in the brain.

\section{Asymmetry of symptomatology in Parkinson's disease}

Because each cerebral hemisphere controls the contralateral side of the body, symptomatology appearing at one hemibody should result from increased neurodegeneration in the contralateral cerebral hemisphere. As PD develops with symptoms on one side of the body, the brain shows increased degeneration in the contralateral hemisphere (Booij et al., 1997; Choe et al., 1998; Wang et al., 2015). As PD progresses, neurodegeneration becomes more diffuse and widespread (Zarei et al., 2013); however, severity of symptoms and neuropathology remains unilateral throughout the disease (Lee et al., 1995; Ropper et al., 2014). It is possible, then, to view PD symptoms as a disruption in interhemispheric balance and to study it in respect to which hemisphere is more affected and what deficits would, therefore, be more expected. Improved understanding of asymmetrical symptom onset may influence the symptom profile and allow for increased predictive accuracy of disease progression and outcome, thus opening the door to personalized and improved therapy in treating PD patients (see Feis et al., 2015; Riederer \& Sian-Hülsmann, 2012). To better understand how PD symptoms may uniquely manifest from asymmetrical neural degeneration, it is important to delineate the overall symptom profile in respect to brain lateralization. The following sections describe motor and several non-motor symptoms of PD in respect to brain laterality and asymmetrical degeneration. 


\section{Motor Symptoms}

PD consists of motor symptom subtypes (tremor dominant [TD] and postural instability/gait difficulty dominant [PIGD]) in which one motor feature (tremor or postural/axial rigidity) is more prominent and, thus, more debilitating (Choi et al., 2018). Tremor is the most recognizable symptom of $\mathrm{PD}$, and patients may have a resting tremor as well as a postural tremor (Jankovic, 2008). Patients with PIGD experience more balance and gait problems, such as festinating gait, which occurs when the body's center of gravity shifts, causing the patient to lose balance and reduce walking to a shuffle to avoid falling (Sveinbjornsdottir, 2016; Ropper et al., 2014). Freezing of Gait (FOG), a motor block in which the individual suddenly feels stuck, is an episodic condition that disrupts balance and is a common cause of falls (Bloem et al., 2004; Okuma, 2014). Different environmental factors may trigger FOG, such as a turn or change in direction, multi-tasking, going through doorways, and approaching a destination (Okuma, 2006; Jankovic, 2008). There is a greater risk for developing FOG with the PIGD subtype (Gao et al., 2020; Giladi et al., 2001), possibly explaining the significantly greater risk of falls in PIGD patients as compared to TD patients (Pelicioni et al., 2019). Additionally, patients may experience painful postural deformities resulting from a number of factors, including axial dystonia and muscular rigidity (Doherty et al., 2011). The unilateral appearance of tremor, rigidity, and bradykinesia are well-known, but asymmetrical axial impairments in balance control (such as FOG), though less often studied, have also been reported (Boonstra et al., 2014; Geurts et al., 2011).

Some studies have investigated the link between motor symptom side of onset in PD and motor/ambulatory prognosis. Baumann et al. (2014) found that patients with right-sided onset 
(RSO) of motor symptoms (symptoms appearing at the right hemibody) are reported to experience more rapid progression of motor symptoms in comparison to patients with left-sided onset (LSO) symptom profile (motor symptoms appearing at the left hemibody). Munhoz et al. (2013) reported an association between LSO and delayed ambulatory inhibition, and Frazzitta et al. (2015) found that patients with RSO had reduced muscle strength compared to LSO patients. Additionally, LSO patients exhibited stronger (i.e., healthier) cortical beta activity responses on Electroencephalogram during movement compared to RSO patients regardless of limb side movement (Heinrichs-Graham et al., 2017). Several studies also report a less favorable prognosis for patients with the PIGD subtype (Appleman et al., 2011; Herman et al., 2015; Jankovic et al., 1990; Jankovic \& Kapadia, 2001; Post et al., 2011; Rajput et al., 1993) and a more favorable prognosis for the TD subtype (Arie et al., 2017; Zetusky et al., 1985). While the reasons as to why the PIGD and possibly RSO profiles produce a less favorable prognosis remain unclear, viewing these profiles in terms of hemispheric lateralization and asymmetrical neural degeneration may provide insight into their differing prognoses.

The more favorable prognosis of LSO patients could result from a relative sparing of the left hemisphere and its specialization in motor processing and planning, especially for ballistic movement (Fisk \& Goodale, 1988; Haaland \& Harrington, 1994; Harrison, 2015a). The left hemisphere plans and allows for timing and sequencing of fine motor movement (Haaland \& Harrington, 1994; Kimura, 1977; Mutha et al., 2013; Winstein \& Pohl, 1995), while the right hemisphere stabilizes the extremity at the target position through control of impedance (Schaefer et al., 2011; Yadav \& Sainburg, 2014). The left hemisphere is crucial for overall motor attention and execution, and dysfunction in the left hemisphere may leave the patient apraxic (Clark et al., 1994; Fisk \& Goodale, 1988; Rushworth et al., 2003). Therefore, patients with LSO and, thus, a 
more preserved functionality of the left hemisphere's motor processing capabilities, may exhibit better control over their motor symptoms and have a better prognosis regarding motor deficits than RSO patients.

Conversely, neurodegeneration of the motor processing areas in the left hemisphere and dysregulation of right hemispheric motor impedance areas may contribute to the development of axial symptoms associated with PIGD, such as FOG. While dysfunction in executive functioning is thought to contribute to FOG (Amboni et al., 2007; Giladi et al., 2007; Naismith et al., 2010), specifically an inappropriate engagement and release of inhibition (Cohen et al., 2014), the inhibition of gait initiation and progression of movement in FOG (Okuma, 2006) may point to increased motor impedance due to right hemisphere hyperactivity. This hypothesis of right hemisphere hyperactivity contributing to FOG is supported by the fact that emotional responses, such as anxiety, stress, and depression, can trigger FOG (Bartels \& Leenders, 2009; Martens et al., 2016; Nutt et al., 2011; Rajput et al., 1993) given the right hemisphere's superiority in processing negatively valanced emotions (Blackhart et al., 2006; Mandal et al., 1991; Pauli et al., 1999). Additionally, a study of physiological changes during FOG found that both heart rate (Maidan et al., 2010) and skin conductance (Mazilu et al., 2015) increased, suggesting an increase in sympathetic activity during FOG and, thus, an increase in right hemispheric activity (see Autonomic dysfunction section). Further, a study by Gilat et al. (2018) found significantly increased connectivity between right amygdala and right putamen in individuals with FOG compared to those without FOG.

Given this information, it may then be inferred that the PIGD subtype is more closely linked to a greater degeneration of the left hemisphere and sparing of the right hemisphere and may, therefore, be more common in the RSO symptom profile. This line of logic may also be 
extended to link the TD subtype to the LSO symptom profile: that is, in theory, TD may be more expected to occur in patients with a greater sparring of left hemisphere motor processing areas.

\section{Autonomic Dysfunction}

Often an early symptom of PD that worsens with disease progression, autonomic dysfunction includes bladder, gastrointestinal (GI), thermoregulation, sexual, and cardiovascular dysfunction (Chen, et al., 2020). As with motor symptoms, hemispheric side of pathology may influence type and severity of autonomic dysfunction: the left hemisphere regulates parasympathetic processes (e.g., lowers blood pressure and heart rate and increases gastric motility for the "rest and digest" state; Guo et al., 2016; Hilz et al., 2001; McCorry, 2007; Oppenheimer et al., 1996; Wittling, 1997) while the right hemisphere regulates sympathetic activity (e.g., increase heart rate, blood pressure, and blood glucose levels in preparation for “flight or fight" responses; Hilz et al., 2001; Julius \& Majahalme, 2000; Mancia et al., 2007; Wittling, 1997, 1998; Oppenheimer et al., 1992, 1996). A disruption in this balance of autonomic functioning can produce dangerous health conditions, and by studying asymmetrical neurodegeneration in regards to the dynamic functioning of the autonomic system, caregivers can be cued to look out for these potentially dangerous conditions that may arise as a result of PD pathology.

For example, due to hemispheric release associated with the proposed shift in contralateral regulatory control, patients with RSO may experience more gastroparesis, leading to reduced appetite, early satiety, weight loss, nausea, bloating, abdominal distension, and reduction in the effects of levodopa by decreasing drug absorption (Cersosimo et al., 2018; Chen et al., 2020; Pfeiffer, 2016). Left hemispheric pathology may also contribute to the constipation 
seen in PD (Pfeiffer, 2011; Jost, 2010); this bowel dysfunction as well as GI immobility could then contribute to the small intestinal bacterial overgrowth seen in over $50 \%$ of PD patients (Porras et al., 2004; Sachdev \& Pimentel, 2013; Tan et al., 2014). Left hemispheric pathology producing increased sympathetic activity may also lead to the hypertension and increased heart rate seen in some patients (Pfeiffer, 2016). Additionally, this increased sympathetic activity may cause dysregulation of glucose levels (Mancia et al., 2007); interestingly, Type 2 Diabetes is associated with an increased risk of developing PD (Hu et al., 2007), possibly implicating diabetes as a preclinical symptom of PD.

\section{Sensory Abnormalities}

Parkinson's Disease patients may develop changes in sensory perceptions, such as in gustation (Doty et al., 2014; Kim et al., 2010; Shah et al., 2009), olfaction (Doty et al., 1988;

Hawkes et al., 1997), and somatosensory (e.g., pain; Valkovic et al., 2015). Pain in PD is of great concern, with over $60 \%$ of patients complaining of pain (Lee et al., 2006; Giuffrida et al., 2005; Valkovic et al., 2015). Additionally, right frontal hyperactivity has been associated with a greater sensitivity to pain (Murray \& Safferstone, 1970; Pauli et al., 1999) and, so, caregivers and therapists may want to look out for an increased pain sensitivity in RSO patients.

Mechanisms behind gustatory dysfunction, such as ageusia (loss of taste), are not well defined but are likely multifactorial, being influenced by medication, olfactory dysfunction, poor oral hygiene, saliva production, depression, and possibly neuropathology (Hoffman et al., 2009; Kashihara et al., 2011; Tarakad \& Jankovic, 2017). Anatomically, gustatory projections enter the ipsilateral medulla with some fibers crossing over to the contralateral side at the mesencephalon level (Harrison, 2015b; Heckmann et al., 2003); it is therefore reasonable to consider gustatory 
disorders and the body side affected by the location of pathology (i.e., brainstem, thalamus, or cortex; Heckmann et al., 2003). For the gustatory system, the left hemisphere appears to be specialized for sensing and appreciating more subjectively pleasant and pleasurable flavors (Bender et al., 2009). Less research exists for the right hemisphere's role in gustatory perception, but it may dominate in sensing intensely bitter (Small, 2001) and perhaps spicy flavors (as capsaicin produces the sensation of burning pain [Caterina et al., 1997, 2000]) or possibly deal with the subjective experience of disagreeable flavors due to its role in negative affect processing (Mandal et al., 1991; Pauli et al., 1999). This lateralization of gustatory perception may be clinically relevant: if, for example, a patient suffered from left hemispheric pathology, they may not appreciate and enjoy the same pleasantly flavored foods they once did. If the patient does not finish meals or refuses to eat, it may seem like a good idea for family members to feed them more of the same foods they once enjoyed in order to encourage eating; however, introducing foods with different and varied (and perhaps more intensely bitter and spicy) flavoring more specialized for the intact right hemisphere preferences may bring relief to an unpleasant dysgeusia. Tailoring the diet in this way can potentially alleviate some concern related to reduced appetite leading to weight loss, weakness, and fatigue.

Additionally, over $70 \%$ of PD patients have anosmia (loss of sense of smell) or hyposmia with over $70 \%$ of these patients unaware of their olfactory deficits (Doty et al., 1988; Hawkes et al., 1997). Olfactory dysfunction is generally considered to be bilateral (Doty, 2012); however, Zucco et al. (2001, 2015) found that patients with RSO had left-sided olfactory deficits in scent recognition and identification, suggesting that olfactory disturbances may show an asymmetric pattern. As in taste, laterality may contribute to the valence of olfactory perception. In a study by Henkin and Levy (2001), imagination of pleasant odors created increased activation in the left 
hemisphere as compared to the right hemisphere, and unpleasant odors as well as unpleasant phantosmias (olfactory hallucination) and phantogeusia (gustatory hallucination) tended to produce more activation in the right hemisphere. A study by Mak et al. (2005) found that a patient with a left insular lesion experienced decreased taste intensity on the ipsilateral tongue but experienced increased intensity on the contralateral right side particularly for strongly affective tastes (e.g., bitter); they also found an increased perceived intensity of unpleasant odors presented to the right nostril. Given this, PD patients with RSO may be more affected by strongly affective tastes and unpleasant odors than would a patient with LSO. Additionally, because smell contributes to taste perception, this increase in unpleasant odor perception may further contribute to the dysgeusia that potentially follows right hemispheric hyperactivity. If this were true, then plugging the nose while eating could help diminish some of the unpleasantness of the dysgeusia.

\section{Visuospatial Dysfunction}

$78 \%$ of PD patients experience at least one symptom of visuospatial dysfunction, such as impairments in spatial perception (Harris et al., 2003; Laudate et al., 2013; Lee et al., 2001b), spatial navigation (Bowen et al., 1972; Davidsdottir et al., 2008), mental rotation (Lee et al., 1998), visuospatial memory (Amick et al., 2006; Possin et al., 2008; Owen et al., 1993), and visuospatial problem solving (Cronin-Golomb \& Braun, 1997). Visuospatial dysfunction is concerning as it may contribute to difficulties with walking and performing activities of daily living (Maeshima et al., 1997); these impairments should, therefore, be evaluated during examinations. As the right hemisphere (particularly the posterior parietal lobe) appears important in performing visuospatial tasks (Benton et al., 1978; Fink et al., 2000; Harris et al., 2000; Ornstein et al., 1980), pathology in this hemisphere should produce more of the visual deficits 
observed in PD. Patients with LSO are, therefore, expected to exhibit more visuospatial dysfunction. LSO patients perform worse on visuospatial tests of navigation (Bowen et al., 1972), memory (Amick et al., 2006), and line bisection and cancellation tests (Laudate et al., 2013; Lee et al., 2001b; Villardita et al., 1983). Those with LSO also saw objects in their left visual field as smaller (Harris et al., 2003) and reported a reduced visual representation of doorways in their left visual field, which could contribute to hesitation and FOG (Lee et al., 2001a).

Perception of spatial relationships is also altered in PD. Patients demonstrate a shift in optic flow by which RSO patients report the left visual field as moving faster, and LSO patients report the same in the right visual field (Davidsdottir et al., 2008) possibly due to a unilateral compression of the visual field (Harris et al., 2003). This change in optic flow produces a bias in which the direction of self-motion appears to move towards the more slowly moving hemifield (Dyre \& Anderson, 1997). Research also shows a shift in the egocentric reference point (ECRP; the point midline of the trunk that divides the spatial fields into left and right hemispaces), which may contribute to hemineglect (Karnath et al., 1991). Both Davidsdottir et al. (2008) and Young et al. (2010) found that PD patients with RSO veered more towards the left, while those with LSO veered towards the right, suggesting that shifts in ECRP may cause dysfunction in coordination of walking and contribute to veering. Therefore, due to the spatial neglect seen in right parietal damage (Heilman \& Van Den Abell, 1980; Karnath, 1997; Mesulam, 2000) in addition to the right hemispheric dominance in parietal activation in optic flow perception (Peuskens, 2001), LSO patients are expected to have increased difficulty with optic flow and ECRP disruption (Cronin-Golomb, 2010). 


\section{Language Dysfunction}

Studies show that PD patients experience significant language impairment. Given the left hemisphere's importance in lexical, semantic, and syntactic aspects of language and speech output (Geschwind, 1970; Vingerhoets \& Stroobant, 1999), damage to this hemisphere may not only leave the patient aphasic (Harrison, 2015d) but also lead to deficits in motoric speech production, such as dysarthria (impairment in speech production due to muscle control; Mackenzie, 2011; Urban et al., 2006; Wise et al., 1999) and apraxia of speech (impairment in motoric planning and programming of speech; Dronkers et al., 1996; Ogar et al., 2005). Hypokinetic and articulatory dysarthria as well as verbal apraxia are common disorders in PD (Brabenec et al., 2017; Caligiuri, 1989; Hirose et al., 1981; Howard et al., 2000; Presotto et al., 2015), and these disorders are expected to occur more so in patients with RSO. For example, speech production is impaired in PD as bradykinesia and rigidity take hold of the vocal apparatus, leading to hypophonic (decreased volume), monotone, and slow speech (Smith \& Caplan, 2018); this disruption in speech acoustics can lead the listener to believe the patient is less interested, less involved, or less happy based on their tone of voice (Jaywant \& Pell, 2009). Other language deficits in PD include those in sentence comprehension (Colman et al., 2011; Kemmerer, 1999; Lieberman et al. 1992), production (Ash et al., 2017), naming and verbal fluency (Cotelli et al., 2007; Hough, 2004; Lewis et al., 1998), and figurative language (Lewis et al., 1998; Monetta \& Pell, 2007). There also exists a particular difficulty with action-word (verb) semantics, production, naming, and identification (Crescentini et al., 2008; Fernandino et al., 2013; Herrera \& Cuetos, 2012; Péran et al., 2009), which appear independent of cognitive status (Bocanegra et al., 2015). This action-word impairment may be the result of deficits in the cortical motor areas, as these areas may be necessary for processing action-word concepts (Fernandino et 
al., 2013). Although few studies have investigated side of onset and language impairment in particular, they seem to suggest greater impairment in RSO patients. For example, Verreyt et al. (2011) found that RSO patients performed worse on language-related tasks and verbal memory compared to LSO patients.

\section{Neuropsychiatric Features}

Given the impairment in emotional processing seen in PD (Ariatti et al., 2008; Gray \& Tickle-Degnen, 2010) and the lateralization of emotion in the brain, it may be beneficial for patients and caregivers to be aware of what emotional and behavioral changes may occur due to asymmetrical neural degeneration. Dysfunction of the left hemisphere, specifically in the frontal lobes, allows for a shift towards right hemispheric hyperactivity that can produce depressive and anxious symptomology (Alajbegovic et al., 2014; Blackhart et al., 2006; Everhart et al., 2002; Vataja et al., 2001; see Hecht, 2010 and Otto et al., 1987). Reports vary, but about 40\% of PD patients experience depression (Aarsland et al., 2009; Farabaugh et al., 2009) and anxiety (Walsh \& Bennett, 2001; Richard et al., 1996). Left hemispheric hypoactivity could also lead to anhedonia (an inability to feel pleasure accompanied by amotivation), as this hemisphere may play more of a role in the experience of pleasure (Bender et al., 2009; Flores-Gutiérrez et al., 2007, 2009; Ohgami et al., 2006; Gagnon \& Peretz, 2000; Henkin \& Levy, 2001). Additionally, some studies report that the right hemisphere plays a role in inhibition of urges, which suggests that hyperactivity here may lead to amotivational and social-withdrawal behaviors (Camprodon et al., 2007; Davidson et al., 1990; Harmon-Jones, 2004; Harrison, 2015c). Foster et al. (2011, 2013) found that duration of illness for RSO, but not LSO, positively correlated with depression and anxiety severity. 
PD patients also show impairment in emotion recognition (Gray \& Tickle-Degnen, 2010). Several studies demonstrated deficits in perceiving facial expressions, particularly for negative emotions such as disgust and fear (Ariatti et al., 2008; Jacobs et al., 1995; Lawrence et al., 2007; Suzuki et al., 2006; Clark et al., 2008; Sprengelmeyer et al., 2013). Alexithymia (a condition that results in deficits in identifying and describing emotions) is seen in $20 \%$ of PD patients (Assogna et al., 2012; Costa et al., 2006, 2010) and may result from right hemispheric dysfunction (Bogdanova \& Cronin-Golomb, 2013; Costa et al., 2007; Jessimer \& Markham, 1997; Spalletta et al., 2001). Patients also struggle with aprosodia (an inability to understand or exhibit emotion in speech), especially with negative affect (Bocklet et al., 2011; Dara et al., 2008; Pell \& Leonard, 2003), which is attributed to right hemisphere pathology (Ahern et al., 1991; Dara et al., 2014; Heilman et al. 1975; Ross \& Mesulam, 1979; Tucker et al., 1977). Because changes in mood, behavior, and personality can be especially difficult for patients and loved ones, being aware of the disease's neuropsychiatric effects may alleviate some level of frustration and potentially encourage earlier detection and treatment of mood symptoms.

\section{Conclusion \& future directions}

There are many more non-motor symptoms of PD, such as sleep disturbances and hallucinations, that could not be fit into one paper. Many of these non-motor symptoms may be lateralized, but insufficient research on brain lateralization makes associative predictions merely speculative. For example, while sleep likely involves extensive activity of both hemispheres, each may play its own dynamic role, and disruption to hemispheric equilibrium may contribute to sleep disturbances; however, research in sleep laterality is inconsistent, and only a few studies have investigated the role of side on symptom onset in relation to sleep disturbances (see, for 
example, Stavitsky et al., 2008). Research into side of symptom onset and non-motor feature prevalence in areas such as sleep, sensation (e.g., audition), and hallucinations will help with treatment and care planning.

Further, research into cognitive decline and side of onset is murky. While some research suggests that the PIGD motor subtype and LSO may produce a more favorable prognosis in terms of motor symptoms, there does not seem to exist as clear a relationship between side of onset and cognitive prognosis. Methodological issues in studies researching laterality in cognitive decline create large barriers to assessing these relationships. Especially problematic is the lack of adequate neuropsychological testing that equally assesses both hemispheres; for example, some studies use only quick screening instrument to assess global cognitive status, such as the Mini Mental State Examination (MMSE) and/or Dementia Rating Scale (DRS), as their primary measure of cognitive decline (see Baumann et al., 2014; Foster et al., 2013; Williams et al., 2007). The MMSE mainly gives insight into the functioning of the left hemisphere (Kupke et al., 1993; Nieuwenhuis-Mark, 2010), and, while the DRS provides a few more tests of right hemispheric functioning, neither test should be used as the sole methodology when evaluating laterality. Therefore, given the dearth of thorough, reliable research into PD laterality and cognitive outcomes, associative relationships cannot be formed. Future studies should include a full neuropsychological battery with assessments in all domains with a particular emphasis on language, visuospatial, and emotion as these are especially lateralized. By standardizing methodology used to study laterality in cognitive decline, data will be more reliable and consistent.

Disregarding the intrinsic nature of the hemispheres disservices the patients who could benefit from improved therapeutics, not only in PD but in any disease or disorder that shows 
asymmetric pathology. The two oppositional hemispheres work together dynamically to produce the intricate processes of cognition and behavior. While this paper focuses on hemispheric differences, it is not meant to neglect the holistic nature of the brain as homologous brain regions often have similar behavioral roles (Milner, 1971); however, the laterality in symptomatology and its relationship to neurodegeneration severely lacks thorough investigation. Both motor and non-motor symptoms of PD are influenced by the asymmetry of neurodegeneration inherent to the disease progression and should not be ignored when researching and treating PD. By incorporating the asymmetric nature of PD into clinical practice and research protocols, patients will benefit from access to predictive symptom profiles, improved personalized treatment plans, and better quality of life.

\section{Disclosure Statement}

In accordance with Taylor \& Francis policy and our ethical obligation as researchers, we are reporting that we have no financial and/or business interests in a company that may be affected by the research reported in the enclosed paper. 


\section{References}

Aarsland, D., Bronnick, K., Alves, G., Tysnes, O. B., Pedersen, K. F., Ehrt, U., \& Larsen, J. P. (2009). The spectrum of neuropsychiatric symptoms in patients with early untreated Parkinson's disease. Journal of Neurology, Neurosurgery \& Psychiatry, 80(8), 928-930. https://doi.org/10.1136/jnnp.2008.166959

Aarsland, D., Zaccai, J., \& Brayne, C. (2005). A systematic review of prevalence studies of dementia in Parkinson's disease. Movement Disorders, 20(10), 1255-1263. https://doi.org/10.1002/mds.20527

Ahern, G. L., Schomer, D. L., Kleefield, J., Blume, H., Cosgrove, G. R., Weintraub, S., \& Mesulam, M. M. (1991). Right Hemisphere Advantage for Evaluating Emotional Facial Expressions. Cortex, 27(2), 193-202. https://doi.org/10.1016/s0010-9452(13)80123-2

Alajbegovic, A., Djelilovicvranic, J., Alajbegovic, S., Nakicevic, A., Todorovic, L., \& Tiriccampara, M. (2014). Post Stroke Depression. Medical Archives, 68(1), 47.

https://doi.org/10.5455/medarh.2014.68.47-50

Amboni, M., Cozzolino, A., Longo, K., Picillo, M., \& Barone, P. (2007). Freezing of gait and executive functions in patients with Parkinson's disease. Movement Disorders, 23(3), 395-400. https://doi.org/10.1002/mds.21850

Amick, M. M., Grace, J., \& Chou, K. L. (2006). Body side of motor symptom onset in Parkinson's disease is associated with memory performance. Journal of the International Neuropsychological Society, 12(5), 736-740. https://doi.org/10.1017/s1355617706060875

Appleman, E. R., Stavitsky, K., \& Cronin-Golomb, A. (2011). Relation of Subjective Quality of Life to Motor Symptom Profile in Parkinson's Disease. Parkinson's Disease, 2011, 1-5. https://doi.org/10.4061/2011/472830 
Ariatti, A., Benuzzi, F., \& Nichelli, P. (2008). Recognition of emotions from visual and prosodic cues in Parkinson's disease. Neurological Sciences, 29(4), 219-227. https://doi.org/10.1007/s10072-0080971-9

Arie, L., Herman, T., Shema-Shiratzky, S., Giladi, N., Hausdorff, J. M. (2017). Do cognition and other non-motor symptoms decline similarly among patients with Parkinson's disease motor subtypes? Findings from a 5-year prospective study. Journal of Neurology, 264, 2149-2157. https://doi.org/10.1007/s00415-017-8605-x

Ash, S., Jester, C., York, C., Kofman, O. L., Langey, R., Halpin, A., Firn, K., Preze, S. D., Chahine, L., Spindler, M., Dahodwala, N., Irwin, D. J., McMillan, C., Weintraub, D., Grossman, M. (2017). Longitudinal decline in speech production in Parkinson's disease spectrum disorders. Brain and Language, 171, 42-51. https://doi.org/10.1016/j.bandl.2017.05.001

Assogna, F., Palmer, K., Pontieri, F. E., Pierantozzi, M., Stefani, A., Gianni, W., Caltagirone, C., Spalletta, G. (2012). Alexithymia Is a Non-Motor Symptom of Parkinson Disease. The American Journal of Geriatric Psychiatry, 20(2), 133-141. https://doi.org/10.1097/jgp.0b013e318209de07

Baba, Y., Putzke, J. D., Whaley, N. R., Wszolek, Z. K., \& Uitti, R. J. (2005). Gender and the Parkinson's disease phenotype. Journal of Neurology, 252(10), 1201-1205. https://doi.org/10.1007/s00415-005-0835-7

Baldereschi, M., Carlo, A. D., Rocca, W. A., Vanni, P., Maggi, S., Perissinotto, E., Grigoletto, F., Inzitari, D. (2000). Parkinson's disease and parkinsonism in a longitudinal study: Two-fold higher incidence in men. Neurology, 55(9), 1358-1363. https://doi.org/10.1212/wnl.55.9.1358

Bartels, A. L., \& Leenders, K. L. (2009). Parkinson's disease: The syndrome, the pathogenesis and pathophysiology. Cortex, 45(8), 915-921. https://doi.org/10.1016/j.cortex.2008.11.010 
Baumann, C. R., Held, U., Valko, P. O., Wienecke, M., \& Waldvogel, D. (2014). Body side and predominant motor features at the onset of Parkinson's disease are linked to motor and nonmotor progression. Movement Disorders, 29(2), 207-213. https://doi.org/10.1002/mds.25650

Bender, G., Veldhuizen, M. G., Meltzer, J. A., Gitelman, D. R., \& Small, D. M. (2009). Neural correlates of evaluative compared with passive tasting. European Journal of Neuroscience, 30(2), 327-338. https://doi.org/10.1111/j.1460-9568.2009.06819.x

Benton, A. L., Varney, N. R., \& Hamsher, K. D. (1978). Visuospatial Judgment. Archives of Neurology, 35(6), 364. https://doi.org/10.1001/archneur.1978.00500300038006

Benowitz, L. I., Bear, D. M., Rosenthal, R., Mesulam, M. M., Zaidel, E., \& Sperry, R. W. (1983). Hemispheric Specialization in Nonverbal Communication. Cortex, 19(1), 5-11. https://doi.org/10.1016/s0010-9452(83)80046-X

Blackhart, G. C., Minnix, J. A., \& Kline, J. P. (2006). Can EEG asymmetry patterns predict future develo pment of anxiety and depression? Biological Psychology, 72(1), 46-50. https://doi.org/10.1016/j.biopsycho.2005.06.010

Bloem, B. R., Hausdorff, J. M., Visser, J. E., \& Giladi, N. (2004). Falls and freezing of gait in Parkinson's disease: A review of two interconnected, episodic phenomena. Movement Disorders, 19(8), 871-884. https://doi.org/10.1002/mds.20115

Bocanegra, Y., García, A. M., Pineda, D., Buriticá, O., Villegas, A., Lopera, F., Gomez, D., GomezArias, C., Cardona, J. F., Trujillo, N., Ibáñez, A. (2015). Syntax, action verbs, action semantics, and object semantics in Parkinson's disease: Dissociability, progression, and executive influences. Cortex, 69, 237-254. https://doi.org/10.1016/j.cortex.2015.05.022 
Bocklet, T., Noth, E., Stemmer, G., Ruzickova, H., \& Rusz, J. (2011). Detection of persons with Parkinson's disease by acoustic, vocal, and prosodic analysis. 2011 IEEE Workshop on Automatic Speech Recognition \& Understanding. https://doi.org/10.1109/asru.2011.6163978

Bogdanova, Y., \& Cronin-Golomb, A. (2013). Alexithymia and Apathy in Parkinson's Disease: Neurocognitive Correlates. Behavioural Neurology, 27(4), 535-545. https://doi.org/10.1155/2013/682393

Booij, J., Tissingh, G., Boer, G. J., Speelman, J. D., Stoof, J. C., Janssen, A. G., Wolters, E. E., van Royen, E. A. (1997). [123I]FP-CIT SPECT shows a pronounced decline of striatal dopamine transporter labelling in early and advanced Parkinson's disease. Journal of Neurology, Neurosurgery \& Psychiatry, 62(2), 133-140. https://doi.org/10.1136/jnnp.62.2.133

Boonstra, T. A., van Vugt, J. P. P., van der Kooij, H., \& Bloem, B. R. (2014). Balance Asymmetry in Parkinson's Disease and Its Contribution to Freezing of Gait. PLoS ONE, 9(7). https://doi.org/10.1371/journal.pone.0102493

Borod, J. C. (1992). Interhemispheric and intrahemispheric control of emotion: A focus on unilateral brain damage. Journal of Consulting and Clinical Psychology, 60(3), 339-348. https://doi.org/10.1037//0022-006x.60.3.339

Bowen, F. P., Hoehn, M. M., \& Yahr, M. D. (1972). Parkinsonism: Alterations in spatial orientation as determined by a route-walking test. Neuropsychologia, 10(3), 355-361. https://doi.org/10.1016/0028-3932(72)90027-9

Brabenec, L., Mekyska, J., Galaz, Z., \& Rektorova, I. (2017). Speech disorders in Parkinson’s disease: early diagnostics and effects of medication and brain stimulation. Journal of Neural Transmission, 124(3), 303-334. https://doi.org/10.1007/s00702-017-1676-0 
Caligiuri, M. (1989). The influence of speaking rate on articulatory hypokinesia in parkinsonian dysarthria. Brain and Language, 36(3), 493-502. https://doi.org/10.1016/0093-934x(89)90080-1

Camprodon, J. A., Martínez-Raga, J., Alonso-Alonso, M., Shih, M.-C., \& Pascual-Leone, A. (2007). One session of high frequency repetitive transcranial magnetic stimulation (rTMS) to the right prefrontal cortex transiently reduces cocaine craving. Drug and Alcohol Dependence, 86(1), 9194. https://doi.org/10.1016/j.drugalcdep.2006.06.002

Caterina, M. J., Leffler, A., Malmberg, A. B., Martin, W. J., Trafton, J., Petersen-Zeitz, K. R., Koltzenburg, M., Basbaum, A. I., Julius, D. (2000). Impaired Nociception and Pain Sensation in Mice Lacking the Capsaicin Receptor. Science, 288(5464), 306-313. https://doi.org/10.1126/science.288.5464.306

Caterina, M. J., Schumacher, M. A., Tominaga, M., Rosen, T. A., Levine, J. D., \& Julius, D. (1997). The capsaicin receptor: a heat-activated ion channel in the pain pathway. Nature, 389(6653), 816824. https://doi.org/10.1038/39807

Cersosimo, M. G., Raina, G. B., Pellene, L. A., Micheli, F. E., Calandra, C. R., \& Maiola, R. (2018). Weight Loss in Parkinson's Disease: The Relationship with Motor Symptoms and Disease Progression. BioMed Research International, 2018, 1-6. https://doi.org/10.1155/2018/9642524

Chaudhuri, K. R., Healy, D. G., \& Schapira, A. H. (2006). Non-motor symptoms of Parkinson's disease: Diagnosis and management. The Lancet Neurology, 5(3), 235-245. https://doi.org/10.1016/s1474-4422(06)70373-8

Chen, Z., Li, G., \& Liu, J. (2020). Autonomic dysfunction in Parkinson's disease: Implications for pathophysiology, diagnosis, and treatment. Neurobiology of Disease, 134, 104700. https://doi.org/10.1016/j.nbd.2019.104700 
Choe, B.-Y., Park, J.-W., Lee, K.-S., Son, B.-C., Kim, M.-C., Kim, B.-S., Suh, T.-S., Lee, H-K., Shinn, K.-S. (1998). Neuronal Laterality in Parkinson's Disease With Unilateral Symptom by In Vivo 1H Magnetic Resonance Spectroscopy. Investigative Radiology, 33(8), 450-455.

https://doi.org/10.1097/00004424-199808000-00005

Choi, S., Kim, B. C., Cho, B., Kang, K. W., Choi, K., Kim, J., Lee, S., Park, M., Kim, M., Cho, K. (2018). Comparison of two motor subtype classifications in de novo Parkinson's disease. Parkinsonism \& Related Disorders, 54, 74-78. https://doi.org/10.1016/j.parkreldis.2018.04.021

Clark, M. A., Merians, A. S., Kothari, A., Poizner, H., Macauley, B., Rothi, L. J. G., \& Heilman, K. M. (1994). Spatial Planning deficits in limb apraxia. Brain, 117(5), 1093-1106. https://doi.org/10.1093/brain/117.5.1093

Clark, U. S., Neargarder, S., \& Cronin-Golomb, A. (2008). Specific impairments in the recognition of emotional facial expressions in Parkinson's disease. Neuropsychologia, 46(9), 2300-2309. https://doi.org/10.1016/j.neuropsychologia.2008.03.014

Cohen, R. G., Kein, K. A., Nomura, M., Fleming, M., Mancini, M., Giladi, N., Nutt, G., Horak, F. B. (2014). Inhibition, executive function, and freezing of gait. Journal of Parkinson's Disease, 45, 1st ser., 111-1228. https://doi.org/10.3233/JPD-130221

Colman, K. S. F., Koerts, J., Stowe, L. A., Leenders, K. L., \& Bastiaanse, R. (2011). Sentence Comprehension and Its Association with Executive Functions in Patients with Parkinson's Disease. Parkinson's Disease, 2011, 1-15. https://doi.org/10.4061/2011/213983

Comer, C. S., Harrison, P. K., \& Harrison, D. W. (2015). The dynamic opponent relativity model: an integration and extension of capacity theory and existing theoretical perspectives on the 
neuropsychology of arousal and emotion. SpringerPlus, 4(1). https://doi.org/10.1186/s40064015-1120-6

Costa, A., Peppe, A., Carlesimo, G. A., Pasqualetti, P., \& Caltagirone, C. (2006). Alexithymia in Parkinson's disease is related to severity of depressive symptoms. European Journal of Neurology, 13(8), 836-841. https://doi.org/10.1111/j.1468-1331.2006.01216.x

Costa, A., Peppe, A., Carlesimo, G. A., Salamone, G., \& Caltagirone, C. (2007). Neuropsychological correlates of alexithymia in Parkinson's disease. Journal of the International Neuropsychological Society,13(6), 980-992. https://doi.org/10.1017/s1355617707071329

Costa, A., Peppe, A., Carlesimo, G. A., Salamone, G., \& Caltagirone, C. (2010). Prevalence and Characteristics of Alexithymia in Parkinson's Disease. Psychosomatics, 51(1), 22-28. https://doi.org/10.1016/s0033-3182(10)70655-1

Cotelli, M., Borroni, B., Manenti, R., Zanetti, M., Arévalo, A., Cappa, S. F., \& Padovani, A. (2007). Action and object naming in Parkinson's disease without dementia. European Journal of Neurology, 14(6), 632-637. https://doi.org/10.1111/j.1468-1331.2007.01797.x

Crescentini, C., Mondolo, F., Biasutti, E., \& Shallice, T. (2008). Supervisory and Routine Processes in Noun and Verb Generation in Nondemented Patients with Parkinson's Disease. Neuropsychologia, 46(2), 434-447. https://doi.org/10.1016/j.neuropsychologia.2007.08.021

Cronin-Golomb, A. (2010). Parkinson's Disease as a Disconnection Syndrome. Neuropsychology Review, 20(2), 191-208. https://doi.org/10.1007/s11065-010-9128-8

Cronin-Golomb, A., \& Braun, A. E. (1997). Visuospatial dysfunction and problem solving in Parkinson's disease. Neuropsychology, 11(1), 44-52. https://doi.org/10.1037//0894-4105.11.1.44 
Dara C, Bang J, Gottesman RF, Hillis AE. (2014) Right hemisphere dysfunction is better predicted by emotional prosody impairments as compared to neglect. Journal of Neurology \& Translational Neuroscience, 2(1), 1037.

Dara, C., Monetta, L., \& Pell, M. D. (2008). Vocal emotion processing in Parkinson's disease: Reduced sensitivity to negative emotions. Brain Research, 1188, 100-111.

https://doi.org/10.1016/j.brainres.2007.10.034

Davidsdottir, S., Wagenaar, R., Young, D., \& Cronin-Golomb, A. (2008). Impact of optic flow perception and egocentric coordinates on veering in Parkinson's disease. Brain, 131(11), 28822893. https://doi.org/10.1093/brain/awn237

Davidson, R. J., Ekman, P., Saron, C. D., Senulis, J. A., \& Friesen, W. V. (1990). Approach-withdrawal and cerebral asymmetry: Emotional expression and brain physiology: I. Journal of Personality and Social Psychology, 58(2), 330-341. https://doi.org/10.1037/0022-3514.58.2.330

de Lau, L., \& Breteler, M. (2006). Epidemiology of Parkinson's disease. The Lancet Neurology, 5(6), 525-535. https://doi.org/10.1016/s1474-4422(06)70471-9

de Lau, L., Giesbergen, P., de Rijk, M., Hofman, A., Koudstaal, P., \& Breteler, M. (2004). Incidence of parkinsonism and Parkinson disease in a general population: The Rotterdam Study. Neurology, 63(7), 1240-1244. https://doi.org/10.1212/01.wnl.0000140706.52798.be

Doherty, K. M., van de Warrenburg, B. P., Peralta, M. C., Silveira-Moriyama, L., Azulay, J.-P., Gershanik, O. S., \& Bloem, B. R. (2011). Postural deformities in Parkinson's disease. The Lancet Neurology, 10(6), 538-549. https://doi.org/10.1016/s1474-4422(11)70067-9

Doty, R. L. (2012). Olfactory dysfunction in Parkinson disease. Nature Reviews Neurology, 8(6), 329339. https://doi.org/10.1038/nrneurol.2012.80 
Doty, R.L., Deems, D.A., Stellar, S. (1988). Olfactory dysfunction in parkinsonism: a general deficit unrelated to neurologic signs, disease stage, or disease duration. Neurology, 38(8):1237-1244. https://doi.org/10.1212/wnl.38.8.1237

Doty, R. L., Nsoesie, M. T., Chung, I., Osman, A., Pawasarat, I., Caulfield, J., Hurtig, H., Silas, J., Dubroff, J., Duda, J., Ying, G., Tekeli, H., Leon-Sarmiento, F. E. (2014). Taste function in early stage treated and untreated Parkinson's disease. Journal of Neurology, 262(3), 547-557. https://doi.org/10.1007/s00415-014-7589-z

Dronkers, N. F. (1996). A new brain region for coordinating speech articulation. Nature, 384(6605), 159-161. https://doi.org/10.1038/384159a0

Dyre, B. P., \& Andersen, G. J. (1997). Image velocity magnitudes and perception of heading. Journal of Experimental Psychology: Human Perception and Performance, 23(2), 546-565. https://doi.org/10.1037/0096-1523.23.2.546

Everhart, D. E., Harrison, D. W., Shenal, B. V., Williamson, J., \& Wuensch, K. L. (2002). Grip-strength, fatigue, and motor perseveration in anxious men without depression. Neuropsychiatry, Neuropsychology, \& Behavioral Neurology, 15(2), 133-142.

Farabaugh, A. H., Locascio, J. J., Yap, L., Weintraub, D., Mcdonald, W. M., Agoston, M., Alpert, J. E., Growdon, j., Fava, M. (2009). Pattern of Depressive Symptoms in Parkinson's Disease. Psychosomatics, 50(5), 448-454. https://doi.org/10.1016/s0033-3182(09)70836-9

Feis, D., Pelzer, E. A., Timmermann, L., \& Tittgemeyer, M. (2015). Classification of symptom-side predominance in idiopathic Parkinson's disease. npj Parkinson's Disease, 1(1). https://doi.org/10.1038/npjparkd.2015.18

Fernandino, L., Conant, L. L., Binder, J. R., Blindauer, K., Hiner, B., Spangler, K., \& Desai, R. H. (2013). Where is the action? Action sentence processing in Parkinson's 
disease. Neuropsychologia, 51(8), 1510-1517.

https://doi.org/10.1016/j.neuropsychologia.2013.04.008

Ferreira, M., \& Massano, J. (2016). An updated review of Parkinson’s disease genetics and clinicopathological correlations. Acta Neurologica Scandinavica, 135(3), 273-284. https://doi.org/10.1111/ane.12616

Fink, G. R., Marshall, J. C., Shah, N. J., Weiss, P. H., Halligan, P. W., Grosse-Ruyken, M., Ziemons, K., Zilles, K., Freund, H.-J. (2000). Line bisection judgments implicate right parietal cortex and cerebellum as assessed by fMRI. Neurology, 54(6), 1324-1331. https://doi.org/10.1212/wnl.54.6.1324

Fisk, J.D., Goodale, M.A. (1988). The effects of unilateral brain damage on visually guided reaching: hemispheric differences in the nature of the deficit. Experimental Brain Research, 72, 425-435. https://doi.org/10.1007/BF00250264

Flores-Gutiérrez, E. O., Díaz, J.-L., Barrios, F. A., Favila-Humara, R., Guevara, M. Á., Río-Portilla, Y. D., \& Corsi-Cabrera, M. (2007). Metabolic and electric brain patterns during pleasant and unpleasant emotions induced by music masterpieces. International Journal of Psychophysiology, 65(1), 69-84. https://doi.org/10.1016/j.ijpsycho.2007.03.004

Flores-Gutiérrez, E. O., Díaz, J.-L., Barrios, F. A., Guevara, M. Á., Río-Portilla, Y. D., Corsi-Cabrera, M., \& Flores-Gutiérrez, E. O. D. (2009). Differential alpha coherence hemispheric patterns in men and women during pleasant and unpleasant musical emotions. International Journal of Psychophysiology, 71(1), 43-49. https://doi.org/10.1016/j.ijpsycho.2008.07.007

Foster, P. S., Drago, V., Crucian, G. P., Sullivan, W. K., Rhodes, R. D., Shenal, B. V., Skoblar, B., Skidmore, F. M., Heilman, K. M. (2011). Anxiety and depression severity are related to right but 
not left onset Parkinson's disease duration. Journal of the Neurological Sciences, 305(1-2), 131135. https://doi.org/10.1016/j.jns.2011.02.023

Foster, P. S., Drago, V., Mendez, K., Witt, J. C., Crucian, G. P., \& Heilman, K. M. (2013). Mood disturbances and cognitive functioning in Parkinson's disease: The effects of disease duration and side of onset of motor symptoms. Journal of Clinical and Experimental Neuropsychology, 35(1), 71-82. https://doi.org/10.1080/13803395.2012.753037

Frazzitta, G., Ferrazzoli, D., Maestri, R., Rovescala, R., Guaglio, G., Bera, R., Volpe, D., Pezzoli, G. (2015). Differences in Muscle Strength in Parkinsonian Patients Affected on the Right and Left Side. Plos One, 10(3). https://doi.org/10.1371/journal.pone.0121251

Gagnon, L., \& Peretz, I. (2000). Laterality effects in processing tonal and atonal melodies with affective and nonaffective task instructions. Brain and Cognition, 43, 206-210. https://doi.org/10.1006/brcg.1999.1135

Gainotti, G. (1972). Emotional Behavior and Hemispheric Side of the Lesion. Cortex, 8(1), 41-55. https://doi.org/10.1016/s0010-9452(72)80026-1

Gao, C., Liu, J., Tan, Y., \& Chen, S. (2020). Freezing of gait in Parkinson's disease: pathophysiology, risk factors and treatments. Translational Neurodegeneration, 9(1). https://doi.org/10.1186/s40035-020-00191-5

Giladi, N., Huber-Mahlin, V., Herman, T., \& Hausdorff, J. M. (2007). Freezing of gait in older adults with high level gait disorders: association with impaired executive function. Journal of Neural Transmission, 114(10), 1349-1353. https://doi.org/10.1007/s00702-007-0772-y

Gilat, M., Martens, K. A. E., Miranda-Domínguez, O., Arpan, I., Shine, J. M., Mancini, M., Fair, D. A., Lewis, S. J. G., Horak, F. B. (2018). Dysfunctional Limbic Circuitry Underlying Freezing of 
Gait in Parkinson's Disease. Neuroscience, 374, 119-132.

https://doi.org/10.1016/j.neuroscience.2018.01.044

Gillies, G.E., Pienaar, I.S., Vohra, S., Qamhaw,i Z. (2014). Sex differences in Parkinson's disease. Frontiers in Neuroendocrinology, 35(3), 370-384.

https://doi.org/10.1016/j.yfrne.2014.02.002

Geschwind, N. (1970). The Organization of Language and the Brain: Language disorders after brain damage help in elucidating the neural basis of verbal behavior. Science, 170(3961), 940-944. https://doi.org/10.1126/science.170.3961.940

Geurts, A., Boonstra, T., Voermans, N., Diender, M., Weerdesteyn, V., \& Bloem, B. (2011). Assessment of postural asymmetry in mild to moderate Parkinson's disease. Gait \& Posture, 33(1), 143-145. https://doi.org/10.1016/j.gaitpost.2010.09.018

Giladi, N., Mcdermott, M. P., Fahn, S., Przedborski, S., Jankovic, J., Stern, M., \& Tanner, C. (2001). Freezing of gait in PD: Prospective assessment in the DATATOP cohort. Neurology, 56(12), 1712-1721. https://doi.org/10.1212/wnl.56.12.1712

Gilat, M., Martens, K. A., Miranda-Domínguez, O., Arpan, I., Shine, J. M., Mancini, M., Fair, D. A., Lewis, S. J. G., Horak, F. B. (2018). Dysfunctional Limbic Circuitry Underlying Freezing of Gait in Parkinson's Disease. Neuroscience, 374, 119-132.

https://doi.org/10.1016/j.neuroscience.2018.01.044

Giuffrida, R., Vingerhoets, F., Bogousslavsky, J., \& Ghika, J. (2005). Syndromes douloureux de la maladie de Parkinson. Revue Neurologique, 161(4), 407-418. https://doi.org/10.1016/S0035$3787(05) 85070-2$

Gray, H. M., \& Tickle-Degnen, L. (2010). A meta-analysis of performance on emotion recognition tasks in Parkinson's disease. Neuropsychology, 24(2), 176-191. https://doi.org/10.1037/a0018104 
Guo, C. C., Sturm, V. E., Zhou, J., Gennatas, E. D., Trujillo, A. J., Hua, A. Y., Crawford, R., Stables, L., Kramer, J. H., Rankin, K., Levenson, R. W., Rosen, H. J., Miller, B. L., Seeley, W. W. (2016). Dominant hemisphere lateralization of cortical parasympathetic control as revealed by frontotemporal dementia. Proceedings of the National Academy of Sciences, 113(17). https://doi.org/10.1073/pnas.1509184113

Haaland, K. Y., \& Harrington, D. L. (1994). Limb-Sequencing Deficits After Left but not Right Hemisphere Damage. Brain and Cognition, 24(1), 104-122. https://doi.org/10.1006/brcg.1994.1006

Haaxma, C. A., Bloem, B. R., Borm, G. F., Oyen, W. J. G., Leenders, K. L., Eshuis, S., Booji, J., Dluzen, D., \& Horstink, M. W. I. M. (2007). Gender differences in Parkinson's disease. Journal of Neurology, Neurosurgery \& Psychiatry, 78(8), 819-824. https://doi.org/10.1136/jnnp.2006.103788

Harmon-Jones, E. (2004). Contributions from research on anger and cognitive dissonance to understanding the motivational functions of asymmetrical frontal brain activity. Biological Psychology, 67(1-2), 51-76. https://doi.org/10.1016/j.biopsycho.2004.03.003

Harris, J., Atkinson, E., Lee, A., Nithi, K., \& Fowler, M. (2003). Hemispace differences in the visual perception of size in left hemiParkinson's disease. Neuropsychologia, 41(7), 795-807. https://doi.org/10.1016/s0028-3932(02)00285-3

Harris, I. M., Egan, G. F., Sonkkila, C., Tochon-Danguy, H. J., Paxinos, G., \& Watson, J. D. G. (2000). Selective right parietal lobe activation during mental rotation. Brain, 123(1), 65-73. https://doi.org/10.1093/brain/123.1.65 
Harrison, D. (2015a). Frontal Lobe Syndromes. In D. W. Harrison (Eds), Brain Asymmetry and Neural Systems (pp. 267-321). Springer International Publishing. https://doi.org/10.1007/978-3-31913069-9_21

Harrison, D. (2015b). Sensation and Perception: Second Functional Unit Revisited. In D. W. Harrison (Eds), Brain Asymmetry and Neural Systems (pp. 85-154). Springer International Publishing . https://doi.org/10.1007/978-3-319-13069-9_21

Harrison, D. (2015c). Social Approach and Social Avoidance. In D. W. Harrison (Eds), Brain Asymmetry and Neural Systems (pp. 383-387). Springer International Publishing . https://doi.org/10.1007/978-3-319-13069-9_21

Harrison, D., (2015d). Syndromes of the Left Brain. In D. W. Harrison (Eds), Brain Asymmetry and Neural Systems (pp. 181-213). Springer International Publishing . https://doi.org/10.1007/978-3319-13069-9_21

Hawkes, C.H., Shephard, B.C., Daniel, S.E. (1997). Olfactory dysfunction in Parkinson's disease. Journal of Neurology, Neurosurgery \& Psychiatry, 62(5):436-446. https://doi.org/10.1136/jnnp.62.5.436

Hecht, D. (2010). Depression and the hyperactive right-hemisphere. Neuroscience Research, 68(2), $77-$ 87. https://doi.org/10.1016/j.neures.2010.06.013

Heckmann, J. G., Heckmann, S. M., Lang, C. J. G., \& Hummel, T. (2003). Neurological Aspects of Taste Disorders. Archives of Neurology, 60(5), 667. https://doi.org/10.1001/archneur.60.5.667

Heilman, K. M., Scholes, R., \& Watson, R. T. (1975). Auditory affective agnosia. Disturbed comprehension of affective speech. Journal of Neurology, Neurosurgery \& Psychiatry, 38(1), 69-72. https://doi.org/10.1136/jnnp.38.1.69 
Heilman, K. M., \& Van Den Abell, T. (1980). Right hemisphere dominance for attention: The mechanism underlying hemispheric asymmetries of inattention (neglect). Neurology, 30(3), 327 327. https://doi.org/10.1212/wnl.30.3.327

Heinrichs-Graham, E., Santamaria, P. M., Gendelman, H. E., \& Wilson, T. W. (2017). The cortical signature of symptom laterality in Parkinson's disease. NeuroImage: Clinical, 14, 433-440. https://doi.org/10.1016/j.nicl.2017.02.010

Henkin, R. I., \& Levy, L. M. (2001). Lateralization of Brain Activation to Imagination and Smell of Odors Using Functional Magnetic Resonance Imaging (fMRI): Left Hemispheric Localization of Pleasant and Right Hemispheric Localization of Unpleasant Odors. Journal of Computer Assisted Tomography, 25(4), 493-514. https://doi.org/10.1097/00004728-200107000-00001

Herman, T., Weiss, A., Brozgol, M., Wilf-Yarkoni, A., Giladi, N., \& Hausdorff, J. M. (2015). Cognitive function and other non-motor features in non-demented Parkinson's disease motor subtypes. Journal of Neural Transmission, 122(8), 1115-1124. https://doi.org/10.1007/s00702014-1349-1

Herrera, E., \& Cuetos, F. (2012). Action naming in Parkinson's disease patients on/off dopamine. Neuroscience Letters, 513(2), 219-222. https://doi.org/10.1016/j.neulet.2012.02.045

Hilz, M. J., Dütsch, M., Perrine, K., Nelson, P. K., Rauhut, U., \& Devinsky, O. (2001). Hemispheric influence on autonomic modulation and baroreflex sensitivity. Annals of Neurology, 49(5), 575584. doi: 10.1002/ana.1006

Hiorth, Y. H., Alves, G., Larsen, J. P., Schulz, J., Tysnes, O.-B., \& Pedersen, K. F. (2016). Long-term risk of falls in an incident Parkinson's disease cohort: the Norwegian ParkWest study. Journal of Neurology, 264(2), 364-372. https://doi.org/10.1007/s00415-016-8365-z 
Hirose, H., Kiritani, S., Ushijima, T., Yoshioka, H., \& Sawashima, M. (1981). Patterns of Dysarthric Movements in Patients with Parkinsonism. Folia Phoniatrica Et Logopaedica, 33(4), 204-215. https://doi.org/10.1159/000265595

Hoffman, H. J., Cruickshanks, K. J., \& Davis, B. (2009). Perspectives on Population-based Epidemiological Studies of Olfactory and Taste Impairment. Annals of the New York Academy of Sciences, 1170(1), 514-530. https://doi.org/10.1111/j.1749-6632.2009.04597.x

Hough, M. S. (2004). Generative word fluency skills in adults with Parkinson's disease. Aphasiology, 18(5-7), 581-588. https://doi.org/10.1080/02687030444000101

Howard, L. A., Binks, M. G., Moore, A., \& Playfer, J. R. (2000). The Contribution of Apraxic Speech to Working Memory Deficits in Parkinson's Disease. Brain and Language, 74(2), 269-288. https://doi.org/10.1006/brln.2000.2345

Hu, G., Jousilahti, P., Bidel, S., Antikainen, R., \& Tuomilehto, J. (2007). Type 2 Diabetes and the Risk of Parkinson's Disease. Diabetes Care, 30(4), 842-847. https://doi.org/10.2337/dc06-2011

Jacobs, D. H., Shuren, J., Bowers, D., \& Heilman, K. M. (1995). Emotional facial imagery, perception, and expression in Parkinson's disease. Neurology, 45(9), 1696-1702. https://doi.org/10.1212/wnl.45.9.1696

Jankovic, J. (2008). Parkinson's disease: clinical features and diagnosis. Journal of Neurology, Neurosurgery \& Psychiatry, 79(4), 368-376. https://doi.org/10.1136/jnnp.2007.131045 Jankovic, J., \& Kapadia, A. S. (2001). Functional Decline in Parkinson Disease. Archives of Neurology, 58(10), 1611. https://doi.org/10.1001/archneur.58.10.1611

Jankovic, J., Mcdermott, M., Carter, J., Gauthier, S., Goetz, C., Golbe, L., Huber, S., Koller, W., Olanow, C., Shoulson, I., Stern, M., Tanner, C., Weiner, W. (1990). Variable expression of 
Parkinson's disease: A base-line analysis of the DAT ATOP cohort. Neurology, 40(10), 15291529. https://doi.org/10.1212/wnl.40.10.1529

Jaywant, A., Pell, M. D. (2009). Listener impressions of speakers with Parkinson's disease. Journal of the International Neuropsychological Society, 16(1), 49-57. https://doi.org/10.1017/s1355617709990919

Jessimer, M., \& Markham, R. (1997). Alexithymia: A Right Hemisphere Dysfunction Specific to Recognition of Certain Facial Expressions? Brain and Cognition, 34(2), 246-258. https://doi.org/10.1006/brcg.1997.0900

Jost, W. H. (2010). Gastrointestinal dysfunction in Parkinson's Disease. Journal of the Neurological Sciences, 289(1-2), 69-73. https://doi.org/10.1016/j.jns.2009.08.020

Julius, S., \& Majahalme, S. (2000). The changing face of sympathetic overactivity in hypertension. Annals of Medicine, 32(5), 365-370. https://doi.org/10.3109/07853890008995939

Karnath, H. O. (1997). Spatial orientation and the representation of space with parietal lobe lesions. Philosophical Transactions of the Royal Society of London. Series B: Biological Sciences, 352(1360), 1411-1419. https://doi.org/10.1098/rstb.1997.0127

Karnath, H. O., Schenkel, P., \& Fischer, B. (1991). Trunk Orientation As The Determining Factor Of The 'Contralateral' Deficit In The Neglect Syndrome And As The Physical Anchor Of The Internal Representation Of Body Orientation In Space. Brain, 114(4), 1997-2014. https://doi.org/10.1093/brain/114.4.1997

Kashihara, K., Hanaoka, A., \& Imamura, T. (2011). Frequency and Characteristics of Taste Impairment in Patients with Parkinson's Disease: Results of a Clinical Interview. Internal Medicine, 50(20), 2311-2315. https://doi.org/10.2169/internalmedicine.50.5935 
Kim, H.-J., Jeon, B. S., Lee, J.-Y., Cho, Y.-J., Hong, K.-S., \& Cho, J.-Y. (2010). Taste function in patients with Parkinson disease. Journal of Neurology, 258(6), 1076-1079. https://doi.org/10.1007/s00415-010-5884-X

Kimura, D. (1977). Acquisition Of A Motor Skill After Left-Hemisphere Damage. Brain, 100(3), 527542. https://doi.org/10.1093/brain/100.3.527

Klineburger, P. C., \& Harrison, D. W. (2015). The dynamic functional capacity theory: A neuropsychological model of intense emotions. Cogent Psychology, 2(1). https://doi.org/10.1080/23311908.2015.1029691

Kemmerer, D. (1999). Impaired Comprehension of Raising-to-Subject Constructions in Parkinson's Disease. Brain and Language, 66(3), 311-328. https://doi.org/10.1006/brln.1999.2022

Kupke, T., Revis, E. S., \& Gantner, A. B. (1993). Hemispheric bias of the mini-mental state examination in elderly males. Clinical Neuropsychologist, 7(2), 210-214. https://doi.org/10.1080/13854049308401524

Laudate, T. M., Neargarder, S., \& Cronin-Golomb, A. (2013). Line bisection in Parkinson's disease: Investigation of contributions of visual field, retinal vision, and scanning patterns to visuospatial function. Behavioral Neuroscience, 127(2), 151-163. https://doi.org/10.1037/a0031618

Lawrence, A. D., Goerendt, I. K., \& Brooks, D. J. (2007). Impaired recognition of facial expressions of anger in Parkinson's disease patients acutely withdrawn from dopamine replacement therapy. Neuropsychologia, 45(1), 65-74. https://doi.org/10.1016/j.neuropsychologia.2006.04.016

Lee, A. C., Harris, J. P., Atkinson, E. A., \& Fowler, M. S. (2001a). Disruption of estimation of bodyscaled aperture width in Hemiparkinson's disease. Neuropsychologia, 39(10), 1097-1104. https://doi.org/10.1016/s0028-3932(01)00032-x 
Lee, A. C., Harris, J. P., Atkinson, E. A., \& Fowler, M. S. (2001b). Evidence from a line bisection task for visuospatial neglect in left hemiparkinson's disease. Vision Research, 41(20), 2677-2686. https://doi.org/ 10.1016/S0042-6989(01)00129-8

Lee, A.C., Harris, J.P., Calvert, J.E. (1998). Impairments of mental rotation in Parkinson's disease. Neuropsychologia, 36(1), 109-114. https://doi.org/10.1016/s0028-3932(97)00017-1

Lee, C. S., Schulzer, M., Mak, E., Hammerstad, J. P., Calne, S., \& Calne, D. B. (1995). Patterns of Asymmetry Do Not Change Over the Course of Idiopathic Parkinsonism: Implications for Pathogenesis. Neurology, 45(3), 435-439. https://doi.org/10.1212/wnl.45.3.435

Lee, M. A., Walker, R. W., Hildreth, T. J., \& Prentice, W. M. (2006). A Survey of Pain in Idiopathic Parkinson's Disease. Journal of Pain and Symptom Management, 32(5), 462-469. https://doi.org/10.1016/j.jpainsymman.2006.05.020

Lewis, F. M., Lapointe, L. L., Murdoch, B. E., \& Chenery, H. J. (1998). Language impairment in Parkinson's disease. Aphasiology, 12(3), 193-206. https://doi.org/10.1080/02687039808249446

Lieberman, P., Kako, E., Friedman, J., Tajchman, J., Feldman, L., \& Jiminez, E. (1992). Speech production, syntax comprehension, and cognitive deficits in Parkinson's disease. Brain and Language, 43(2), 169-189. https://doi.org/10.1016/0093-934x(92)90127-z

Luria, A. R. (1970). The Functional Organization of the Brain. Scientific American, 222(3), 66-78. https://doi.org/10.1038/scientificamerican0370-66

Mackenzie, C. (2011). Dysarthria in stroke: A narrative review of its description and the outcome of intervention. International Journal of Speech-Language Pathology, 13(2), 125-136. https://doi.org/10.3109/17549507.2011.524940 
Maeshima, S., Itakura, T., Nakagawa, M., Nakai, K., \& Komai, N. (1997). Visuospatial Impairment And Activities Of Daily Living In Patients With Parkinson's Disease. American Journal of Physical Medicine \& Rehabilitation, 76(5), 383-388. https://doi.org/10.1097/00002060-199709000-00007

Maidan, I., Plotnik, M., Mirelman, A., Weiss, A., Giladi, N., \& Hausdorff, J. M. (2010). Heart rate changes during freezing of gait in patients with Parkinson's disease. Movement Disorders, 25(14), 2346-2354. https://doi.org/10.1002/mds.23280

Mak, Y. E., Simmons, K. B., Gitelman, D. R., \& Small, D. M. (2005). Taste and olfactory intensity perception changes following left insular stroke. Behavioral Neuroscience, 119(6), 1693-1700. https://doi.org/10.1037/0735-7044.119.6.1693

Mancia, G., Bousquet, P., Elghozi, J. L., Esler, M., Grassi, G., Julius, S., Reid, J., Van Zwieten, P. A. (2007). The sympathetic nervous system and the metabolic syndrome. Journal of Hypertension, 25(5), 909-920. https://doi.org/10.1097/hjh.0b013e328048d004

Mandal, M., Tandon, S., \& Asthana, H. (1991). Right Brain Damage Impairs Recognition of Negative Emotions. Cortex, 27(2), 247-253. https://doi.org/10.1016/s0010-9452(13)80129-3

Martens, K., Hall, J., Gilat, M., Georgiades, M., Walton, C., \& Lewis, S. (2016). Anxiety is associated with freezing of gait and attentional set-shifting in Parkinson's disease: A new perspective for early intervention. Gait \& Posture, 49, 431-436. https://doi.org/10.1016/j.gaitpost.2016.07.182

Martinez-Martin, P., Falup Pecurariu, C., Odin, P. van Hilten, J.J., Antonini, A., Rojo-Abuin, J.M., Borges, V., Trenkwalder, C., Aarsland, D., Brooks. D.J., Chaudhuri, K.R. (2012). Gender-related differences in the burden of non-motor symptoms in Parkinson's disease. Journal of Neurology, 259, 1639-1647. https://doi.org/10.1007/s00415-011-6392-3

Mazilu, S., Calatroni, A., Gazit, E., Mirelman, A., Hausdorff, J. M., \& Troster, G. (2015). Prediction of Freezing of Gait in Parkinson's From Physiological Wearables: An Exploratory Study. IEEE 
Journal of Biomedical and Health Informatics, 19(6), 1843-1854.

https://doi.org/10.1109/jbhi.2015.2465134

McCorry, L. K. (2007). Physiology of the Autonomic Nervous System. American Journal of Pharmaceutical Education, 71(4), 78. https://doi.org/10.5688/aj710478

Mesulam, M.-M. (2000). Attentional networks, confusional states, and neglect syndromes. In M. M. Mesulam (Ed.), Principles of behavioral and cognitive neurology (p. 174-256). Oxford University Press.

Milner, B. (1971). Interhemispheric Differences In The Localization Of Psychological Processes In Man. British Medical Bulletin, 27(3), 272-277.

https://doi.org/10.1093/oxfordjournals.bmb.a070866

Monetta, L., \& Pell, M. D. (2007). Effects of verbal working memory deficits on metaphor comprehension in patients with Parkinson's disease. Brain and Language, 101(1), 80-89. https://doi.org/10.1016/j.band1.2006.06.007

Munhoz, R. P., Espay, A. J., Morgante, F., Li, J., Teive, H. A., Dunn, E., Gallin, E., Litvan, I. (2013). Long-duration Parkinson's disease: Role of lateralization of motor features. Parkinsonism \& Related Disorders, 19(1), 77-80. https://doi.org/10.1016/j.parkreldis.2012.07.008

Murray, F. S., \& Safferstone, J. F. (1970). Pain threshold and tolerance of right and left hands. Journal of Comparative and Physiological Psychology, 71(1), 83-86. https://doi.org/10.1037/h0028963 Mutha, P. K., Haaland, K. Y., \& Sainburg, R. L. (2013). Rethinking Motor Lateralization: Specialized but Complementary Mechanisms for Motor Control of Each Arm. PLoS ONE, 8(3). https://doi.org/10.1371/journal.pone.0058582 
Naismith, S. L., Shine, J. M., \& Lewis, S. J. (2010). The specific contributions of set-shifting to freezing of gait in Parkinson's disease. Movement Disorders, 25(8), 1000-1004. https://doi.org/10.1002/mds.23005

Nieuwenhuis-Mark, R. E. (2010). The Death Knoll for the MMSE: Has It Outlived Its Purpose? Journal of Geriatric Psychiatry and Neurology, 23(3), 151-157.

https://doi.org/10.1177/0891988710363714

Nutt, J. G., Bloem, B. R., Giladi, N., Hallett, M., Horak, F. B., \& Nieuwboer, A. (2011). Freezing of gait: Moving forward on a mysterious clinical phenomenon. The Lancet Neurology, 10(8), 734744. https://doi.org/10.1016/s1474-4422(11)70143-0

Ogar, J., Slama, H., Dronkers, N., Amici, S., \& Gorno-Tempini, M. L. (2005). Apraxia of Speech: An overview. Neurocase, 11(6), 427-432. https://doi.org/10.1080/13554790500263529

Ohgami, Y., Kotani, Y., Tsukamoto, T., Omura, K., Inoue, Y., Aihara, Y., \& Nakayama, M. (2006). Effects of monetary reward and punishment on stimulus-preceding negativity. Psychophysiology, 43(3), 227-236. https://doi.org/10.1111/j.1469-8986.2006.00396.x

Okuma, Y. (2006). Freezing of gait in Parkinson's disease. Journal of Neurology, 253(S7), vii27-vii32. https://doi.org/10.1007/s00415-006-7007-2

Okuma, Y. (2014). Freezing of Gait and Falls in Parkinson's Disease. Journal of Parkinson's Disease, 4(2), 255-260. https://doi.org/10.3233/jpd-130282

Oppenheimer, S. M., Gelb, A., Girvin, J. P., \& Hachinski, V. C. (1992). Cardiovascular effects of human insular cortex stimulation. Neurology, 42(9), 1727-1727. https://doi.org/10.1212/wnl.42.9.1727 
Oppenheimer, S. M., Kedem, G., \& Martin, W. M. (1996). Left-insular cortex lesions perturb cardiac autonomic tone in humans. Clinical Autonomic Research, 6(3), 131-140. https://doi.org/10.1007/bf02281899

Ornstein, R., Johnstone, J., Herron, J., \& Swencionis, C. (1980). Differential right hemisphere engagement in visuospatial tasks. Neuropsychologia, 18(1), 49-64. https://doi.org/10.1016/00283932(80)90083-4

Otto, M. W., Yeo, R. A., \& Dougher, M. J. (1987). Right hemisphere involvement in depression: Toward a neuropsychological theory of negative affective experiences. Biological Psychiatry, 22(10), 1201-1215. https://doi.org/10.1016/0006-3223(87)90028-x

Owen, A. M., Beksinska, M., James, M., Leigh, P. N., Summers, B. A., Marsden, C. D., Quinn, N. P, Sahakian, B. J., Robbins, T. W. (1993). Visuospatial memory deficits at different stages of Parkinson's disease. Neuropsychologia, 31(7), 627-644. https://doi.org/10.1016/00283932(93)90135-m

Parkinson, J., (1817). An essay on the Shaking Palsy. London: Sherwood, Neely, and Jones.

Pauli, P., Wiedemann, G., \& Nickola, M. (1999). Pain sensitivity, cerebral laterality, and negative affect. Pain, 80(1), 359-364. https://doi.org/10.1016/s0304-3959(98)00231-0

Pelicioni, P. H. S., Menant, J. C., Latt, M. D., \& Lord, S. R. (2019). Falls in Parkinson’s Disease Subtypes: Risk Factors, Locations and Circumstances. International Journal of Environmental Research and Public Health, 16(12), 2216. https://doi.org/10.3390/ijerph16122216

Pell, M. D., \& Leonard, C. L. (2003). Processing emotional tone from speech in Parkinson's disease: A role for the basal ganglia. Cognitive, Affective, \& Behavioral Neuroscience, 3(4), 275-288. https://doi.org/10.3758/cabn.3.4.275 
Péran, P., Cardebat, D., Cherubini, A., Piras, F., Luccichenti, G., Peppe, A., Caltagirone, C., Rascol, O1, Démonet, J., Sabatini, U. (2009). Object naming and action-verb generation in Parkinson’s disease: A fMRI study. Cortex, 45(8), 960-971. https://doi.org/10.1016/j.cortex.2009.02.019

Peuskens, H., Sunaert, S., Dupont, P., Hecke, P. V., \& Orban, G. A. (2001). Human Brain Regions Involved in Heading Estimation. The Journal of Neuroscience, 21(7), 2451-2461. https://doi.org/10.1523/jneurosci.21-07-02451.2001

Pfeiffer, R. F. (2011). Gastrointestinal dysfunction in Parkinson's disease. Parkinsonism \& Related Disorders, 17(1), 10-15. https://doi.org/10.1016/j.parkreldis.2010.08.003

Pfeiffer, R. F. (2016). Non-motor symptoms in Parkinson's disease. Parkinsonism \& Related Disorders, 22. https://doi.org/10.1016/j.parkreldis.2015.09.004

Porras, M., Martín, M. T., Soler, M., \& Vergara, P. (2004). Intestinal motor disorders associated with cyclical bacterial overgrowth in a rat model of enteritis. American Journal of PhysiologyGastrointestinal and Liver Physiology, 287(1). https://doi.org/10.1152/ajpgi.00513.2003

Possin, K. L., Filoteo, J. V., Song, D. D., \& Salmon, D. P. (2008). Spatial and object working memory deficits in Parkinson's disease are due to impairment in different underlying processes. Neuropsychology, 22(5), 585-595. https://doi.org/10.1037/a0012613

Post, B., Muslimovic, D., van Geloven, N., Speelman, J. D., Schmand, B., \& de Haan, R. J. (2011). Progression and prognostic factors of motor impairment, disability and quality of life in newly diagnosed Parkinson's disease. Movement Disorders, 26(3), 449-456. https://doi.org/10.1002/mds.23467

Presotto, M., Olchik, M. R., Shuh, A. F. S., \& Rieder, C. R. M. (2015). Assessment of Nonverbal and Verbal Apraxia in Patients with Parkinson's Disease. Parkinson's Disease, 2015, 1-8. https://doi.org/10.1155/2015/840327 
Rajput, A. H., Pahwa, R., Pahwa, P., \& Rajput, A. (1993). Prognostic significance of the onset mode in parkinsonism. Neurology, 43(4), 829-829. https://doi.org/10.1212/wnl.43.4.829

Reijnders, J. S. A. M., Ehrt, U., Lousberg, R., Aarsland, D., \& Leentjens, A. F. G. (2009). The association between motor subtypes and psychopathology in Parkinson's disease. Parkinsonism \& Related Disorders, 15(5), 379-382. https://doi.org/10.1016/j.parkreldis.2008.09.003

Richard, I. H., Schiffer, R. B., \& Kurlan, R. (1996). Anxiety and Parkinson's disease. The Journal of Neuropsychiatry and Clinical Neurosciences, 8(4), 383-392. https://doi.org/10.1176/jnp.8.4.383

Riederer, P., \& Sian-Hülsmann, J. (2012). The significance of neuronal lateralisation in Parkinson's disease. Journal of Neural Transmission, 119(8), 953-962. https://doi.org/10.1007/s00702-0120775-1

Ropper, H., Samuels, A., \& Klein, P. (2014). Degenerative Diseases of the Nervous System. In Ropper, H., Samuels, A., \& Klein, P. (Eds.) Adam and Victor's Principles of Neurology. (pp. 1060-1132) New York: McGraw-Hill.

Ross, E. D., \& Mesulam, M. M. (1979). Dominant Language Functions of the Right Hemisphere? Archives of Neurology, 36(3), 144. https://doi.org/10.1001/archneur.1979.00500390062006

Rushworth, M., Johansen-Berg, H., Göbel, S., \& Devlin, J. (2003). The left parietal and premotor cortices: Motor attention and selection. NeuroImage, 20. doi:10.1016/j.neuroimage.2003.09.011

Sachdev, A. H., \& Pimentel, M. (2013). Gastrointestinal bacterial overgrowth: pathogenesis and clinical significance. Therapeutic Advances in Chronic Disease, 4(5), 223-231.

https://doi.org/10.1177/2040622313496126 
Sackeim, H. A., Greenberg, M. S., Weinmen, A. L., Gur, R. C., Hungerbuhler, J. P., \& Geschwind, N. (1982). Hemispheric Asymmetry in the Expression of Positive and Negative Emotions. Archives of Neurology, 39(4), 210. https://doi.org/10.1001/archneur.1982.00510160016003

Schaefer, S. Y., Mutha, P. K., Haaland, K. Y., \& Sainburg, R. L. (2011). Hemispheric Specialization for Movement Control Produces Dissociable Differences in Online Corrections after Stroke. Cerebral Cortex, 22(6), 1407-1419. https://doi.org/10.1093/cercor/bhr237

Schapira, A. H., Chaudhuri, K. R., \& Jenner, P. (2017). Non-motor features of Parkinson disease. Nature Reviews Neuroscience, 18(8), 509-509. https://doi.org/10.1038/nrn.2017.91

Shah, M., Deeb, J., Fernando, M., Noyce, A., Visentin, E., Findley, L. J., \& Hawkes, C. H. (2009). Abnormality of taste and smell in Parkinson's disease. Parkinsonism \& Related Disorders, 15(3), 232-237. https://doi.org/10.1016/j.parkreldis.2008.05.008

Silberman, E.K., Weingartner, H. (1986). Hemispheric lateralization of functions related to emotion. Brain and Cognition, 5(3), 322-353. https://doi.org/10.1016/0278-2626(86)90035-7

Small, D. M. (2001). Changes in Taste Intensity Perception Following Anterior Temporal Lobe Removal in Humans. Chemical Senses, 26(4), 425-432. https://doi.org/10.1093/chemse/26.4.425

Smith, K. M., \& Caplan, D. N. (2018). Communication impairment in Parkinson's disease: Impact of motor and cognitive symptoms on speech and language. Brain and Language, 185, 38-46. https://doi.org/10.1016/j.bandl.2018.08.002

Spalletta, G., Pasini, A., Costa, A., De Angelis, D., Ramundo, N., Paolucci, S., \& Caltagirone, C. (2001). Alexithymic Features in Stroke: Effects of Laterality and Gender. Psychosomatic Medicine, 63(6), 944-950. https://doi.org/10.1097/00006842-200111000-00013 
Sprengelmeyer, R., Young, A., Mahn, K., Schroeder, U., Woitalla, D., Büttner, T., Kuhn, W., Przuntek, H. (2003). Facial expression recognition in people with medicated and unmedicated Parkinson's disease. Neuropsychologia, 41(8), 1047-1057. https://doi.org/10.1016/s0028-3932(02)00295-6

Stavitsky, K., Mcnamara, P., Durso, R., Harris, E., Auerbach, S., \& Cronin-Golomb, A. (2008).

Hallucinations, Dreaming, and Frequent Dozing in Parkinson Disease: Impact of Righthemisphere Neural Networks. Cognitive and Behavioral Neurology, 21(3), 143-149. https://doi.org/10.1097/wnn.0b013e318185e698

Suzuki, A., Hoshino, T., Shigemasu, K., \& Kawamura, M. (2006). Disgust-specific impairment of facial expression recognition in Parkinson's disease. Brain, 129(3), 707-717.

https://doi.org/10.1093/brain/aw1011

Sveinbjornsdottir, S. (2016). The clinical symptoms of Parkinson's disease. Journal of Neurochemistry, 139, 318-324. https://doi.org/10.1111/jnc.13691

Tarakad, A., \& Jankovic, J. (2017). Anosmia and Ageusia in Parkinson's Disease. International Review of Neurobiology Nonmotor Parkinson's: The Hidden Face - The Many Hidden Faces, 133, 541556. https://doi.org/10.1016/bs.irn.2017.05.028

Tan, A. H., Mahadeva, S., Thalha, A. M., Gibson, P. R., Kiew, C. K., Yeat, C. M., Ng., S. W., Ang, S. P., Chow, S. K., Tan, C. T., Yong, S. Y., Marras, C., Fox, S., Lim, S. (2014). Small intestinal bacterial overgrowth in Parkinson's disease. Parkinsonism \& Related Disorders, 20(5), 535-540. https://doi.org/10.1016/j.parkreldis.2014.02.019

Tucker, D. M., Watson, R. T., \& Heilman, K. M. (1977). Discrimination and evocation of affectively intoned speech in patients with right parietal disease. Neurology, 27(10), 947-947. https://doi.org/10.1212/wnl.27.10.947 
Tysnes, O., \& Storstein, A. (2017). Epidemiology of Parkinson's disease. Journal of Neural Transmission, 124(8), 901-905. https://doi.org/10.1007/s00702-017-1686-y

Urban, P. P., Rolke, R., Wicht, S., Keilmann, A., Stoeter, P., Hopf, H. C., \& Dieterich, M. (2006). Lefthemispheric dominance for articulation: a prospective study on acute ischaemic dysarthria at different localizations. Brain, 129(3), 767-777. https://doi.org/10.1093/brain/awh708

Valkovic, P., Minar, M., Singliarova, H., Harsany, J., Hanakova, M., Martinkova, J., \& Benetin, J. (2015). Pain in Parkinson's Disease: A Cross-Sectional Study of Its Prevalence, Types, and Relationship to Depression and Quality of Life. Plos One, 10(8).

https://doi.org/10.1371/journal.pone.0136541

Vataja, R., Pohjasvaara, T., Leppävuori, A., Mäntylä, R., Aronen, H. J., Salonen, O., Kaste, M., Erkinjuntti, T. (2001). Magnetic Resonance Imaging Correlates of Depression After Ischemic Stroke. Archives of General Psychiatry, 58(10), 925. https://doi.org/10.1001/archpsyc.58.10.925 Verreyt, N., Nys, G.M.S., Santens, P., Vingerhoets, G. (2011). Cognitive Differences Between Patients with Left-sided and Right-sided Parkinson's Disease. A Review. Neuropsychology Review, 21, 405-424. https://doi.org/10.1007/s11065-011-9182-x

Villardita, C., Smirni, P., \& Zappala, G. (1983). Visual Neglect in Parkinson's Disease. Archives of Neurology, 40(12), 737-739. https://doi.org/10.1001/archneur.1983.04050110055008

Vingerhoets, G., \& Stroobant, N. (1999). Lateralization of Cerebral Blood Flow Velocity Changes During Cognitive Tasks. Stroke, 30(10), 2152-2158. https://doi.org/10.1161/01.str.30.10.2152

Walsh, K., \& Bennett, G. (2001). Parkinson's disease and anxiety. Postgraduate Medical Journal, 77(904), 89-93. https://doi.org/10.1136/pmj.77.904.89

Wang, J., Yang, Q. X., Sun, X., Vesek, J., Mosher, Z., Vasavada, M., Chu, J., Kanekar, S., Shivkumar, V., Venkiteswaran, K., Subramanian, T. (2015). MRI evaluation of asymmetry of nigrostriatal 
damage in the early stage of early-onset Parkinson's disease. Parkinsonism \& Related Disorders, 21(6), 590-596. https://doi.org/10.1016/j.parkreldis.2015.03.012

Williams, D. R., \& Litvan, I. (2013). Parkinsonian Syndromes. CONTINUUM: Lifelong Learning in Neurology, 19, 1189-1212. https://doi.org/10.1212/01.con.0000436152.24038.e0

Williams, L. N., Seignourel, P., Crucian, G. P., Okun, M. S., Rodriguez, R. L., Skidmore, F. M., Foster, P. S., Jacobson, C. E., Romrell, J., Bowers, D., Fernandez, H. H. (2007). Laterality, region, and type of motor dysfunction correlate with cognitive impairment in Parkinson's disease. Movement Disorders, 22(1), 141-144. https://doi.org/10.1002/mds.21220

Williams, D. R., Watt, H. C., \& Lees, A. J. (2006). Predictors of falls and fractures in bradykinetic rigid syndromes: a retrospective study. Journal of Neurology, Neurosurgery \& Psychiatry, 77(4), 468-473. https://doi.org/10.1136/jnnp.2005.074070

Winstein, C., \& Pohl, P. (1995). Effects of unilateral brain damage on the control of goal-directed hand movements. Experimental Brain Research, 105(1). https://doi.org/10.1007/bf00242191

Wise, R., Greene, J., Büchel, C., \& Scott, S. (1999). Brain regions involved in articulation. The Lancet, 353(9158), 1057-1061. https://doi.org/10.1016/s0140-6736(98)07491-1

Wittling, W. (1997). Brain Asymmetry and Autonomic Control of the Heart. European Psychologist, 2(4), 313-327. https://doi.org/10.1027/1016-9040.2.4.313

Wittling, W., Block, A., Schweiger, E., \& Genzel, S. (1998). Hemisphere Asymmetry in Sympathetic Control of the Human Myocardium. Brain and Cognition, 38(1), 17-35. https://doi.org/10.1006/brcg.1998.1000

Wooten, G. F., Currie, L. J., Bovbjerg, V. E., Lee, J. K., \& Patrie, J. (2004). Are men at greater risk for Parkinson's disease than women? Journal of Neurology, Neurosurgery \& Psychiatry, 75(4), 637-639. https://doi.org/10.1136/jnnp.2003.020982 
Yadav, V., \& Sainburg, R. L. (2014). Limb Dominance Results from Asymmetries in Predictive and Impedance Control Mechanisms. PLoS ONE, 9(4). https://doi.org/10.1371/journal.pone.0093892

Young, D. E., Wagenaar, R. C., Lin, C.-C., Chou, Y.-H., Davidsdottir, S., Saltzman, E., \& CroninGolomb, A. (2010). Visuospatial perception and navigation in Parkinson's disease. Vision Research, 50(23), 2495-2504. https://doi.org/10.1016/j.visres.2010.08.029

Zarei, M., Ibarretxe-Bilbao, N., Compta, Y., Hough, M., Junque, C., Bargallo, N., Tolosa, E., \& Martí, M. J. (2013). Cortical thinning is associated with disease stages and dementia in Parkinson's disease. Journal of neurology, neurosurgery, and psychiatry, 84(8), 875-881. https://doi.org/10.1136/jnnp-2012-304126

Zetusky, W. J., Jankovic, J., \& Pirozzolo, F. J. (1985). The heterogeneity of Parkinson's disease: Clinical and prognostic implications. Neurology, 35(4), 522-522. https://doi.org/10.1212/wnl.35.4.522

Zucco, G. M., Rovatti, F., \& Stevenson, R. J. (2015). Olfactory asymmetric dysfunction in early Parkinson patients affected by unilateral disorder. Frontiers in Psychology, 6. https://doi.org/10.3389/fpsyg.2015.01020

Zucco, G., Zeni, M. T., Perrone, A., \& Piccolo, I. (2001). Olfactory Sensitivity in Early-Stage Parkinson Patients Affected by More Marked Unilateral Disorder. Perceptual and Motor Skills, 92(3), 894898. https://doi.org/10.2466/pms.2001.92.3.894 